sensitireness to any reference to the sexual change. With it come various vaso-motor disturbances, morbid blushes, flushings, attacks of giddiness, tinnitus, retinal hyperxmias, laryngeal neuroses, coldness of the extremities, feadache, general languor, ovarian, sacral and coccygeal pain, palpitation, breathlessness, cardiac intermission, digestive errors, and chemical urinary changes in specific gravity, quantity of urea and chlorides. It is only natural that, when any such exciting or depressing causes exist, irritability, or some erraticism of temper, demeanour, conduct, or the assumption of an unusual attitude to friends should occasionally declare itself. It is at such times that the suggestion of some slighting term as "neurotic" becomes unjust and cruel. Any of these states may become aggravated and merge into attitudes of inaptness and irresistible fatigue, of excitability and irritability, or nervousness and apathy, of apprehension and brooding, of antipathies and unwarrantable inferences, together with obsessions as to various ailments and pains, or the fear of the committal of some wrong and sin. Then we are confronted with the truly neurasthenic woman and have to use all our tact and knowledge to prevent a transition into the further alienistic states of " phobias," melancholia, hysteria, hypochondria-in short, some type of actual or borderland insanity.

\section{Principles of Treatment.}

There is not time to discuss more than the principles of treatment when neurasthenic symptoms show themselves, either at puberty or the climacteric. There is one cardinal principle so far as the gynæcologist is concerned which must have a first claim on every practitioner who has at either period to treat such a case. "Take nothing for granted" must be his motto. At puberty his judgment will be taxed as to when a pelvic examination is called for and justified, and a decision will have to be made in the presence of persistent amenorrhœa, dysmenorrhoea, menorrhagia, backache, or some vaginal discharge.

It does not do to send a girl to Spa or Schwalbach for amenorrhoea, or to dose her with emmenagogues who has an abnormal introitus, or in whom the uterus or the ovaries are absent; or to treat her with sedatives for dysmenorrhcea when all the time there is a stenosed canal or a retroverted aterus. In the same way, during the menopause, to trifle with the signs of disease in vaginal discharge, hæmorrhage, pain. bowel and bladder complication or locomotor troubles and to ascribe their presence to a climacteric neurosis and say the woman is a neurasthenic, and then awake to find a uterine or ovarian tumour, malignant degeneration, displaced kianneys or other organic complication, is not a pleasant position either for doctor or patient. The one thing we want to be careful in the neurasthenic girl is any sexual suggestion. To arouse a morbid introspection of the pelvic organs is above all things to be aroided. We have to realise, as insisted on by Sigmund Freud, that there is a causal relationship 'twixt sexual activities and psychic neurosis. So we avoid all experiences that direct attention to these organs. On the other hand, judgment and inquiry from friends will direct when an examination under anæsthesia is called for and the condition of the genitalia thas to be ascertained. There is no such difficulty in the instance of a woman for whose complainings we are consulted during the menopause. Examination here, when local signs and symptoms are present, is imperative, and the first step to relieve the nerve disorder is the treatment and cure of whatever associated affection of the genitalia or other organ is present.

Reverting to puberty, having cleared the ground by the elimination of a genital or other source of the nervous phenomena present, the next step is attention to the girl's moral, intellectual, and physical hygiene. This needs a careful inquiry into her domestic and school life, hours of study, corfinement, exercise, and recreation. In short, our first therapeutic step is an insight into the temperament of the girl and a critical survey of her environment, removing her from, or neutralising when possible, any harmful sources of mental disquietude, excitation, and irritation. Such mental and moral prophylaxis, aided by general hygienic measures in attention to the bowel, bathing, diet, exercise, and recreation, prepares the way for the rectification of any local disorder or neurosis, and especially the regularity and character of her sexual functions.

In the climacteric our first difficulty is to get hold of the right threads in the tangled skein of physical ailments and mental exaggerations which we have to unravel. By a process of clinical exclusion we separate the real from the fanciful and trace the subjective to its objective origin. Analytically we isolate the sexual, digestive, and nervous disturbances present, and synthetically we piece these together so as to obtain a correct picture of the woman out of the multitude of impressions she is anxious to convey of herself, her ailments, and grievances.

Eliminating the need for any operative interference we are free to deal with the main contributory factors in the neurasthenia of the menopause-menorrhagic and metrorrhagic losses, pain, digestive disturbances and constipation, affections of the special senses, and insomnia. Modern therapeutics and pharmacology furnish us with ample means of dealing specially and successfully with all of these predisposing and sustaining causes of neurasthenia, and with these remedial aids of treatment you are as familiar as myself. I would just add that in the neuroses of the meno. pause lutein extract is the most important of all the more recent therapeutic remedies. I have used various ovarian preparations. I have had them of use in some cases and been disappointed in others. In neurasthenic conditions I have found bornyval of considerable value, and as nerve sedatives both adalin and bromural.

Harley-street, $\mathbf{w}$.

\section{HYOSCINE-MORPHIA AN ESTHESIA FOR ALCOHOL INJECTION IN NEURALGIA.}

BY WILFRED HARRIS, M.D. CANTAB., F.R.C.P. LOND.,

PHYSICIAN TO ST. MART'S HOSPITAL, AND TO THE HOSPITAL FOR NERTOUS DISEASES, MAIDA VALE.

THE treatment of severe and intractable trigeminal neuralgia, or tic douloureux, by alcohol injection has now become fully established as the most practical and efficient remedy for this disease, since its first introduction in Munich ten years ago. Schlösser, who first used it, and his followers in other countries, such as Ostwald, Léry and Baudouin, and Sicard in Paris, and Kiliani, Patrick, and others in America, have all practised the method without the use of any anæs. thetic other than a small percentage of stovaine or cocaine mixed with the alcohol, and perhaps a spray of ethyl chloride to freeze the site of skin puncture. I have myself practised alcohol injection for trigeminal neuralgia for nearly five years, and in this period I have thus treated 112 cases of this disease, besides numerous cases of supraorbital and other forms of neuralgia, and I have tried many different methods of making the injection.

From the very first $I$ doubted the possibility of finding with a needle the nerve trunks of the three divisions of the fifth nerve, and of injecting them with alcohol, especially at their deep foramina of exit from the skull, without causing so much pain as to make it a practical impossibility for a large proportion of subjects, especially women of a nervous type and already worn out with pain. I have never used Schlösser's method of reaching the deep foramina, the foramen ovale and foramen rotundum, by intra-oral puncture, owing to the impossibility of sterilising the buccal or pharyngeal mucous membrane or of sealing the puncture made by the needle, and the consequent risk of sepsis. I have always used the route described by Lévy and Baudouin and also by Sicard, in which the needle is thrust through the side of the cheek underneath the zygoma into the zygomatic fossa.

In making the injection for the third division at the foramen ovale, after piercing the skin the needle traverses the masseter and external pterygoid muscles, and very little pain is so far produced, although considerable difficulty will be experienced unless these muscles are relaxed; for this reason nitrous oxide anæsthesia, or even gas and oxygen, is not suitable, owing to muscular spasm induced. If no general anæsthetic is given the patient should be encouraged not to clench the jaws. When the needle has been passed inwards to a distance of about $1 \frac{1}{2}$ inches considerable pain is usually experienced, and this is very little diminished, in my experience, by injection of eucaine solution. In some patients, indeed, the pain produced by the manipulation of the needle at this depth while searching for the foramen ovale is sometimes quite intolerable. My practice, therefore, at first was 
to do all injections for the foramen ovale in women, and for those men who preferred it, under chloroform anæsthesia. This method has the advantage of complete painlessness, but I have almost discarded it now for two reasons: firstly, that it is impossible to be quite certain when the needle reaches the foramen ovale in the majority of instances, if the patient is quite unconscious; and secondly, that the amount of alcohol injected is quite arbitrary and is not determined by the effect produced of anæsthesia of the lower lip and jaw. I should here like to make a protest against the rapid method of injecting that I am informed is used by some surgeons and others. This method is likely only to bring the treatment into disrepute, as when done in this manner far more often than not the nerve is not hit, no anæsthesia is produced, and the pain may be either not relieved at all or be made much worse. I recognised from the first that the only satisfactory proof that the nerve had been properly injected is anæsthesia of the skin and mucous membrane in the distribution of the nerve. Strong alcohol when injected into the nerve trunk instantly causes destruction of the nerve fibres with which it comes into contact; the clinical evidence of this is anrsthesia of the part to all forms of sensation, and motor paralysis of any muscles supplied by the nerve with motor fibres, and later reaction of degeneration in the electrical testing of these muscles.

Under chloroform it is a difficult and slow process to make certain whether the nerve has been properly injected, and this knowledge can only be obtained by discontinuing the administration of the chloroform and allowing the patient gradually to come round. Then, when the conjunctival reflex has become brisk, the patient will react and show signs of discomfort if pricked sharply with a pin upon the lower lip or chin on the sound side. When this reflex has become definitely established the lower lip on the operated side is similarly pricked, and if no reaction is obtained, after repeating the test, it may be considered proved that the nerve is now anæsthetic and has been properly injected. Occasionally, indeed, it may be found that even after the injection of only 1 c.c. in this manner into the nerve in the foramen ovale there is dense anæsthesia produced over the whole fifth nerve distribution, indicating that the Gasserian ganglion itself has been injected, either by the needle having been pushed through the foramen into the ganglion, or else by the alcohol having infiltrated upwards through the root of the third division into the ganglion. Fither of these conditions may occur, as I have shown many times in the dead body, by injecting a solution of methylene blue. This depth of anæsthesia may or may not diminish, after a few minutes or hours, on the first and second divisions-namely, on the forehead, eye, and cheek. When that is the case no harm can result, but if, as may happen, the anæsthesia on the first division remains deep and persistent, then there is the danger of keratitis and ulceration of the cornea from the anæsthesia of the eye. These points, therefore, emphasise the importance of performing the injection while the patient is sufficiently conscious to be able to answer all questions, when tested by the pin for the presence of anæsthesia. I find that a combination of hyoscine and morphine answers the purpose admirably.

As a rule, I give $\frac{1}{3}$ gr. of morphia with $1 / 150$ gr. of hyoscine hypodermically into the arm 20 minutes before commencing the injection process. In this interval the patient should be made to lie down and keep quite quiet, and encouraged to let sleep come if possible. I have used this method now for a considerable number of cases during the last 15 months, and I have been impressed with the restfulness and apparent absence of all pain during the process. When the needle is approaching the foramen ovale the patient usually shows some symptoms of sensitiveness, though it is not until the nerve is actually struck that a tingling sensation is felt in the lower lip and tongue; when this occurs the stylet should be removed from the needle and a syringe filled with a $3 \frac{1}{2}$ per cent. eucaine solution fitted on, and a few drops then slowly injected. If there is considerable resistance to the push of the piston the point of the needle may be within the nerve, but if no resistance is felt the point is certainly not in the nerve, and the needle should then be moved slightly in different directions until it is again thought the foramen has been reached, when again a few drops of eucaine should be injected. If now there is resistance to the push of the piston the syringe should be changed for another filled with 90 per cent. alcohol, and after the lapse of half a minute a few drops of the spirit should now be injected slowly into the same spot, great care having been taken to hold the needle quite steady. The patient will usually feel some burning sensation which may be reflected to the lip and tongue; but this is not always so, nor does the patient always complain of pain along the distribution of the nerve when the needle is first pushed into it, the only pain complained of sometimes being referred deeply at the site of puncture. That this is so I have proved a great many times by the resulting deep anæsthesia after the injection of the third division at the foramen ovale, and also of the infraorbital nerve, when no pain whatever along the distribution of either of these nerves has been produced, either by the puncture of the nerve, or by its subsequent injection with alcohol. This seems difficult to understand, and I should certainly not bave believed it possible had I not proved it over and over again. It is a point of some importance, because, when the injection is being made and the nerve is being searched for without chloroform anæsthesia, the operator may be put off making his injection because he has never been able to produce the characteristic pain along the distribution of the nerve when the point of his needle reaches it, and thus, although his needle may be correctly placed within the nerve, he may withdraw it and search elsewhere in the hope of producing this characteristic pain. In this way I am convinced that in several of my earlier cases I missed injecting the nerve when using no general anæsthetic, though the injection was perfectly successful and deep anæsthesia was produced when done under chloroform.

Almost instantly, as soon as a few drops of alcohol have been injected into the nerve, sensation of touch and pinprick becomes blunted on the lip, and slowly, two or three drops at a time, more spirit is injected until the anæsthesia is complete and the pinprick is not felt at all even as pressure. Usually 1 to $1 \frac{1}{2}$ c.c. are required to produce this effect. After each injection of a few drops of the spirit the lip and chin should be tested for sensation with a pin, and this method of trial-injection and test-anæsthesia is, I am perfectly convinced, the only satisfactory way of getting good results.

For the injection of the second division in the sphenomaxillary fossa chloroform anæsthesia should never be used, as in this case the needle can rarely be inserted into the foramen rotundum itself, and for this reason the nerve is a much more difficult one to puncture fairly and inject than is the third division at the foramen ovale. Moreover, considerable damage may be done in this region by the carèless operator, and severe hæmatoma has been set up from puncture of the internal maxillary artery, or diplopia lasting for months from the injection damagingthe ocular nerves at the sphenoidal fissure, though I have never myself had these results. As a rule the searching for this nerve is much less painful than is the corresponding process for the third division at the foramen ovale, and there is consequently less necessity for a general anæsthetic. However, the extraordinary calming effect of the hyoscine and morphine is most valuable, and patients who are suffering severe spasms of pain, or who are very nervous, will keep quite quiet and peaceful during the whole process, and yet will be able to answer at once to the skin tests for anæsthesia. As soon as the injection has been completed they will usually go to sleep quite readily for two or three hours, when, if necessary, they may be allowed to get up and go home. Injection of the supraorbital nerve also is an extremely painful process if the nerve is punctured properly, and in my opinion it should never be done without the help of this method of anæsthesia.

Of ill-effects of hyoscine and morphia I have seen none except in one case - that of a patient over 70 years of age, who, as I afterwards learnt, was known to be very susceptible to hypnotic and analgesic drugs. In her case, in which $\frac{1}{3}$ gr. of morphia was used with $1 / 150 \mathrm{gr}$. of hyoscine, the respiration became temporarily slowed, with cyanosis, some one and a half hours after the injection, though she soon recovered completely. Vomiting may occur also in some patients, but this tendency may be diminished by the addition of atropine, 1/75 gr., to the preliminary injection.

When using the hyoscine-morphine anæsthetic I prefer that the patient should be in bed, and the services of a nurse are advisable, both for getting ready sterilised towels, \&c., and to stay with the patient for a couple of hours afterwards. Wimpole-street, $\mathrm{W}$. 